\title{
The Effect of Increases in User Weight and Road Slope on Energy Consumption in Disabled Vehicle Driven with PMSM
}

\author{
F. A. KAZAN* and R. AKKAYA
}

\begin{abstract}
In this study, the effect of increases in user weight and road slope on energy consumption $(\mathrm{Wh} / \mathrm{km})$ value of a disabled vehicle driven with permanent magnet synchronous motor (PMSM) was investigated. In order to digitize this effect, a test system consisting of a data reading card and an interface program prepared in Visual $C$ \# was developed. In this way, information about the disabled vehicle and the road was collected instantly during the test process and visualized in the interface. Then experimental studies were carried out on two roads with different slopes with users of different weights. Finally, by using the obtained results, the effect of increases in road slope and user weight on the energy consumption of the vehicle was demonstrated by numerical data. By using these results, the numerical simulations of battery-operated disabled vehicles can be calibrated and much more realistic simulation results can be obtained in future studies.
\end{abstract}

Index Terms - Data acquisition card, disabled vehicle, energy consumption, road slope, $\mathrm{Wh} / \mathrm{km}$.

\section{INTRODUCTION}

$\mathrm{E}$ NERGY CONSUMPTION $(\mathrm{Wh} / \mathrm{km})$ values of disabled vehicles are very important issues for people who use these vehicles. Because disabled vehicle users want to go as far as possible on a single charge. To achieve this, either a larger capacity battery or a more efficient motor must be used in the vehicle. These are additional costs. However, choosing a motor taking into account the environment where the vehicle will be used, and user weight are solutions that are simple and do not incur any additional costs. In order to implement these simple solutions, it is necessary to know the effect of the

FATIH ALPASLAN KAZAN, is with Department of Aviation Electrical and Electronic of Selçuk University, Konya, Turkey, (e-mail: akazan@selcuk.edu.tr).

iD https://orcid.org/0000-0002-5461-0117

*Corresponding Author.

RAMAZAN AKKAYA, is with Department of Electrical and Electronic Engineering of Konya Technical University, Konya, Turkey, (e-mail: rakkaya@ktun.edu.tr).

iD https://orcid.org/0000-0002-6314-1500

Manuscript received August 21, 2020; accepted October 03, 2020. DOI: $\underline{10.17694 / \mathrm{bajece} .783455}$ increase in road slope and user weight on the energy consumption of the disabled vehicle.

The powers of the motors to be mounted on electric vehicles are determined by taking into account the climbing angle of the vehicle and some forces affecting the vehicle. These forces that oppose the movement of the vehicle; aerodynamic (air) resistance, rolling resistance, acceleration resistance and uphill resistance.

Similar points need to be taken into account when determining the power of the motor to be fitted on batteryoperated wheelchairs. In [1], the power of a motor designed to carry $120 \mathrm{~kg}$ load on the battery-operated wheelchair was calculated by considering the above-mentioned forces. As a result of the calculations, it has been found that the motor to be mounted to the disabled vehicle should produce $16.25 \mathrm{Nm}$, $10 \mathrm{Nm}$ and $3.75 \mathrm{Nm}$ of torque on $+20^{\circ}, 0^{\circ}$ and $-20^{\circ}$ roads, respectively. This means that every $1^{\circ}$ change in road slope causes a change by $3.125 \%$ in torque. The literature was searched to find similar studies examining the change of the vehicle's parameters in relation to the road slope in the batteryoperated disabled vehicles.

In [2], the effect of road slope on the energy drawn from the battery in electric cars is theoretically investigated. In the investigation, it is foreseen that the total electricity consumption of the vehicle will increase by $13.58 \%$ on $1^{\circ}$ road slope. However, since the simulated vehicle is a car, the reflection of the change in user weight on this value has not taken into consideration.

In the literature searches made for this purpose, studies in which different solutions are produced for those who do not have hands or arms attract attention. For example, controlling of the disabled vehicle with mouth movement [3], sound [4-7], eyes [8-11], and head movements [12-16] are some of them. Using fuzzy logic controller instead of traditional controller [17, 18], examining the human factor [19], examining the vibration of the vehicle under different road conditions [20], measuring the mechanical and electrical impedances of the vehicle with sensors [21], using efficient motors to increase the vehicle's range [22, 23], detection of road slope with sensor [24] or without sensor [25] are some of the other studies in this area.

In this study, the effect of road slope and user weight on energy consumption in a disabled vehicle driven with permanent magnet synchronous motor (PMSM) was obtained 
by conducting experimental studies. For this purpose, the test system, which was previously designed by the authors [26] to test disabled vehicles driven by permanent magnet direct motor in the laboratory, has been developed to allow disabled vehicles driven with PMSM to be tested in real environments conditions. Then experimental studies were carried out on different sloped roads with users of different weights. Using the obtained data, the effect of the increases in road slope and user weight on energy consumption has been revealed with numerical data.

\section{DESIGNED TEST SYSTEM AND COMPONENTS}

In the designed test system, battery current, inverter current, motor current, battery and inverter voltages, ambient and motor surface temperatures, road slope and vehicle speed are measured every second and sent to the computer. The data sent to the computer are both monitored and recorded at an interface prepared in $\mathrm{C} \#$. The block diagram of the designed test system is given in Fig. 1. The components of the system are also detailed below.

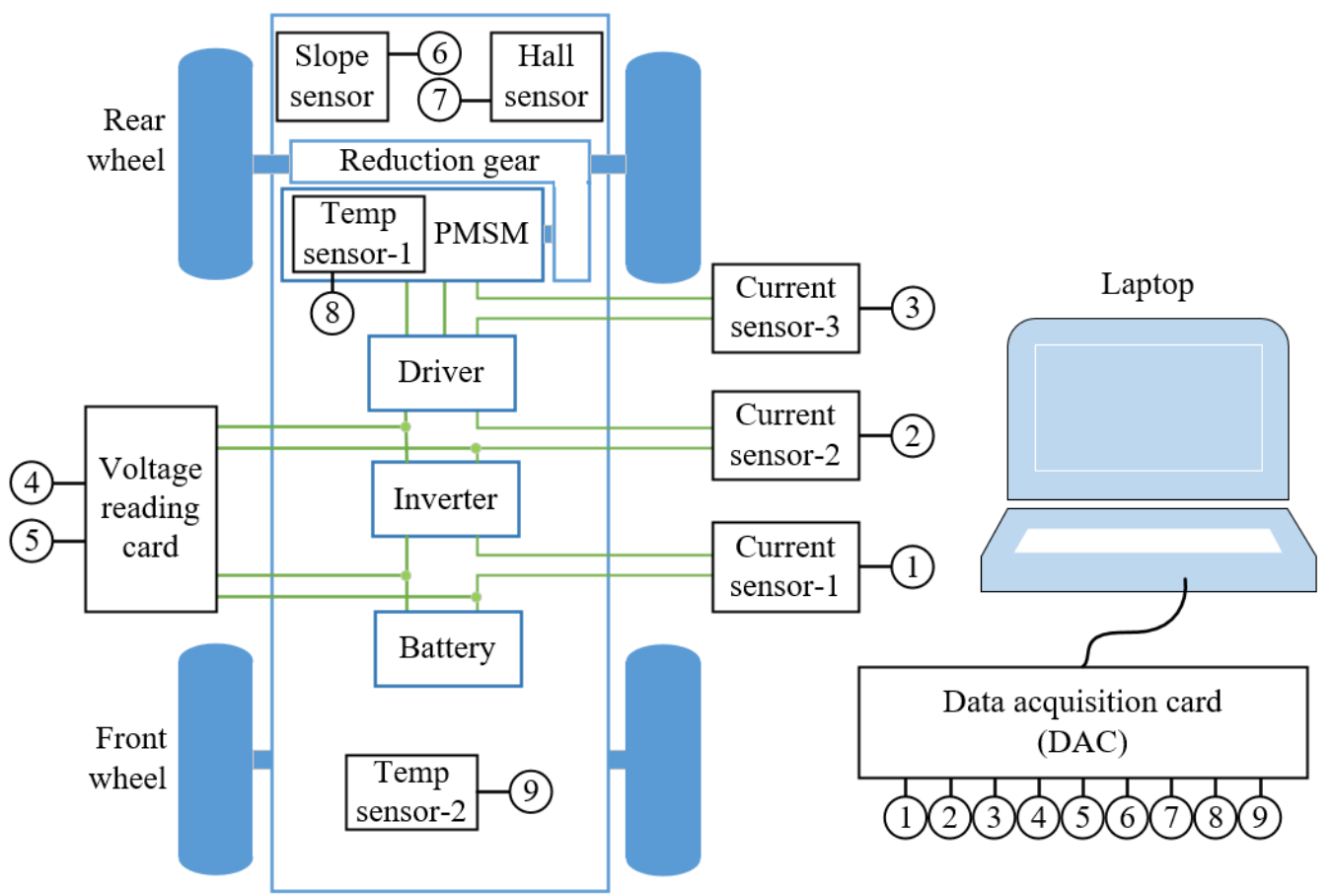

Fig. 1. The block diagram of the designed test system.

\section{A. Measurement of Vehicle Speed}

In order to obtain the energy consumption values of the disabled vehicle, the distance travelled by the vehicle must be known. This information can be obtained by performing experimental studies on a route whose distance is known, or the distance travelled on any route can be obtained by measuring the vehicle speed. Speed measurement can be achieved by fixing the encoder directly or indirectly to the wheel shaft. However, this will require additional changes to the wheel shaft. In this study, it was preferred to measure by using the Hall sensor and magnets instead of speed measurement by making any changes in the physical structure of the vehicle. For this purpose, the A1101 series Hall sensor manufactured by the company named Allegro was used.

To minimize the error in speed measurement as much as possible, it is necessary to place the magnets on the wheel as often as possible. To minimize the error in speed measurement as much as possible, it is necessary to place the magnets on the wheel as often as possible. However, if the distance between the magnets goes below a certain value, the sensor gives an erroneous output. In the tests performed to determine the most suitable magnet number, the number has determined to be 24 . For this reason, 24 magnets have placed on the rim of the right rear wheel. The sensor has placed closest to the wheel so that the distance between them is less than $1 \mathrm{~cm}$ when the sensor is aligned with the magnet. The placed sensor and magnets are shown in Fig. 2.

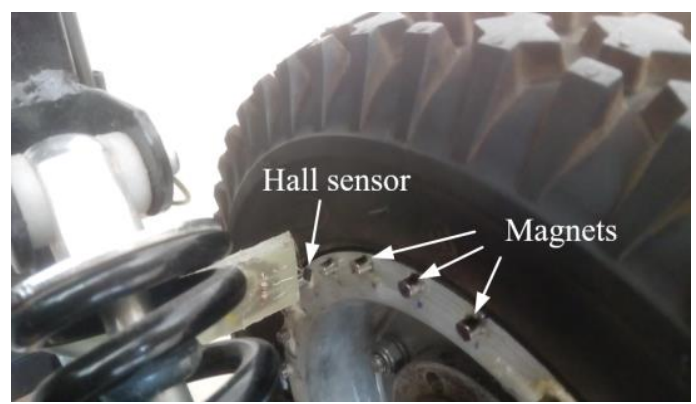

Fig. 2. Physical location of the Hall sensor and magnets.

\section{B. Current Measurement}

ACS712 series current sensors, which can be procured as a module for current measurement, have been chosen. It is sufficient to connect the outputs of the sensors to the analogue inputs of the microcontroller to be used for measurement. 


\section{Voltage Measurement}

In order to both minimize the effect of temperature and provide insulation, LV25P type voltage sensor produced by the company named LEM has used for voltage measurement. LV25P, which can measure AC and DC voltage and needs symmetrical supply, produces an output current that varies according to the magnitude of the voltage at its input. The voltage at the ends of the resistor connected to the low voltage side of this sensor can be easily measured by connecting it to any analogue input of the microcontroller to be used. The voltage reading card, which designed and realized for measuring the voltages of the battery and inverter, is given in Fig. 3.

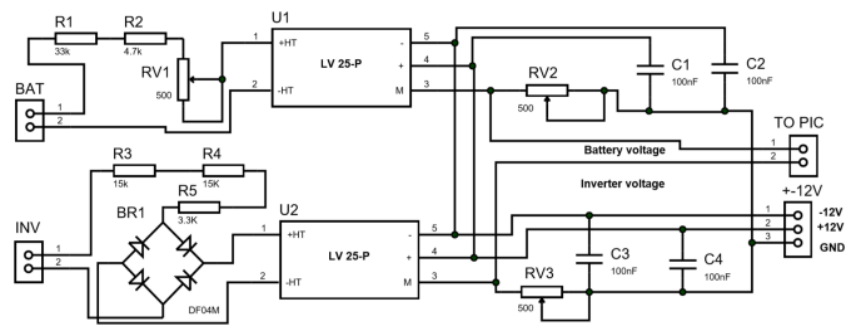

(a)

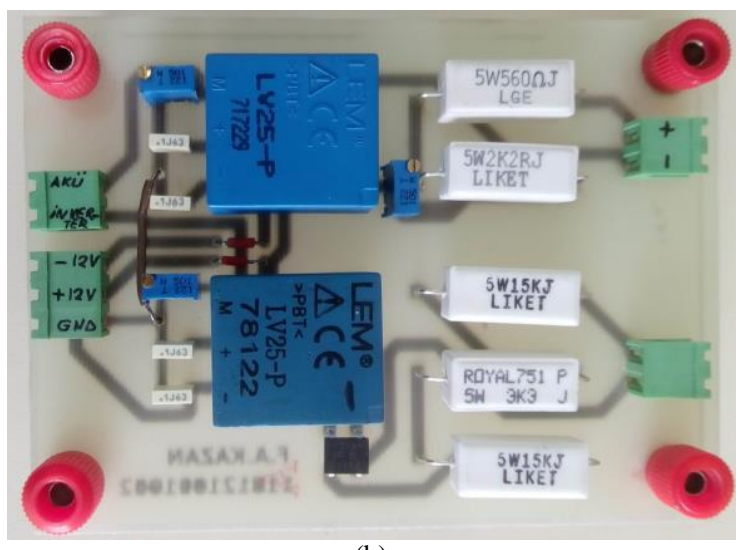

(b)

Fig. 3. Circuit board designed to measure the voltages (a) The open-circuit diagram (b) Final form of the board.

\section{Measurement of Road Slope}

SCA61T-FAHH1G inclination sensor, which can measure the slope within $\pm 30^{\circ}$ limits and with a precision of $0.0025^{\circ}$, was used in order to detect the slope of the road where disabled vehicles are used. This sensor, which can give analogue output, produces an oscillating output when used on a vibrating surface or when exposed to accelerated motion.

\section{E. Data Acquisition Card}

A data acquisition card was designed to ensure that both the data is displayed on the LCD screen and transferred to the computer via USB in real-time after reading the voltages, currents, temperatures, road slope and vehicle speed. PIC18F4550 was preferred as the microcontroller on the board and was operated at $48 \mathrm{MHz}$ by using PLL (Phase Locked Loop) feature. The data acquisition card are given in Fig. 4.

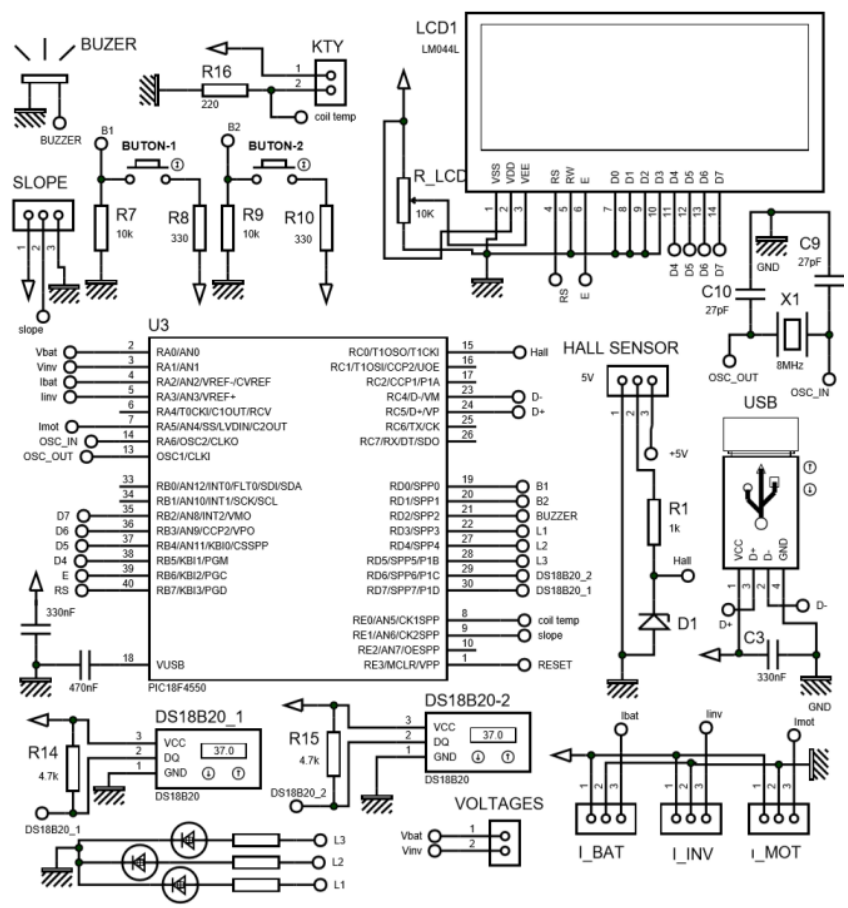

(a)

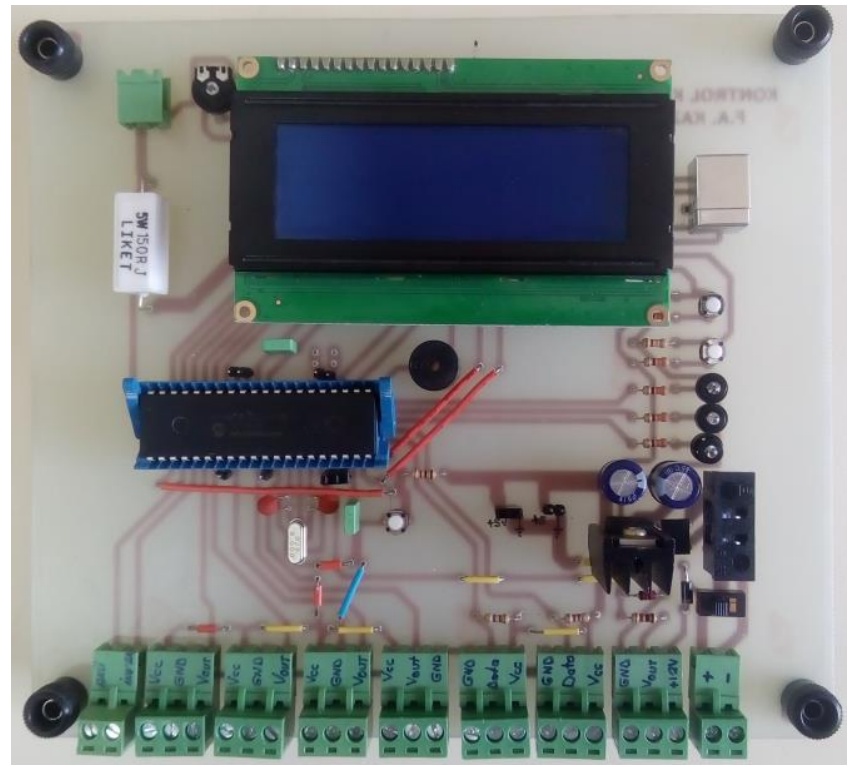

(b)

Fig. 4. The data acquisition card (a) The open-circuit diagram (b) Final form of the board.

\section{F. Data Reading Interface Program}

An interface was designed in the Visual $\mathrm{C \#}$ program to receive the data to be sent by the data acquisition card, to display and store it on the computer, and to graph some required data simultaneously. The interface was designed according to electric mobility scooter models which have different wheel diameters and different reducer ratios and driven by PMSM. The screenshot taken at the moment of the simulation of the data acquisition card from the designed data reading interface program is given in Fig. 5. 
BALKAN JOURNAL OF ELECTRICAL \& COMPUTER ENGINEERING， Vol. 9, No. 1, January 2021

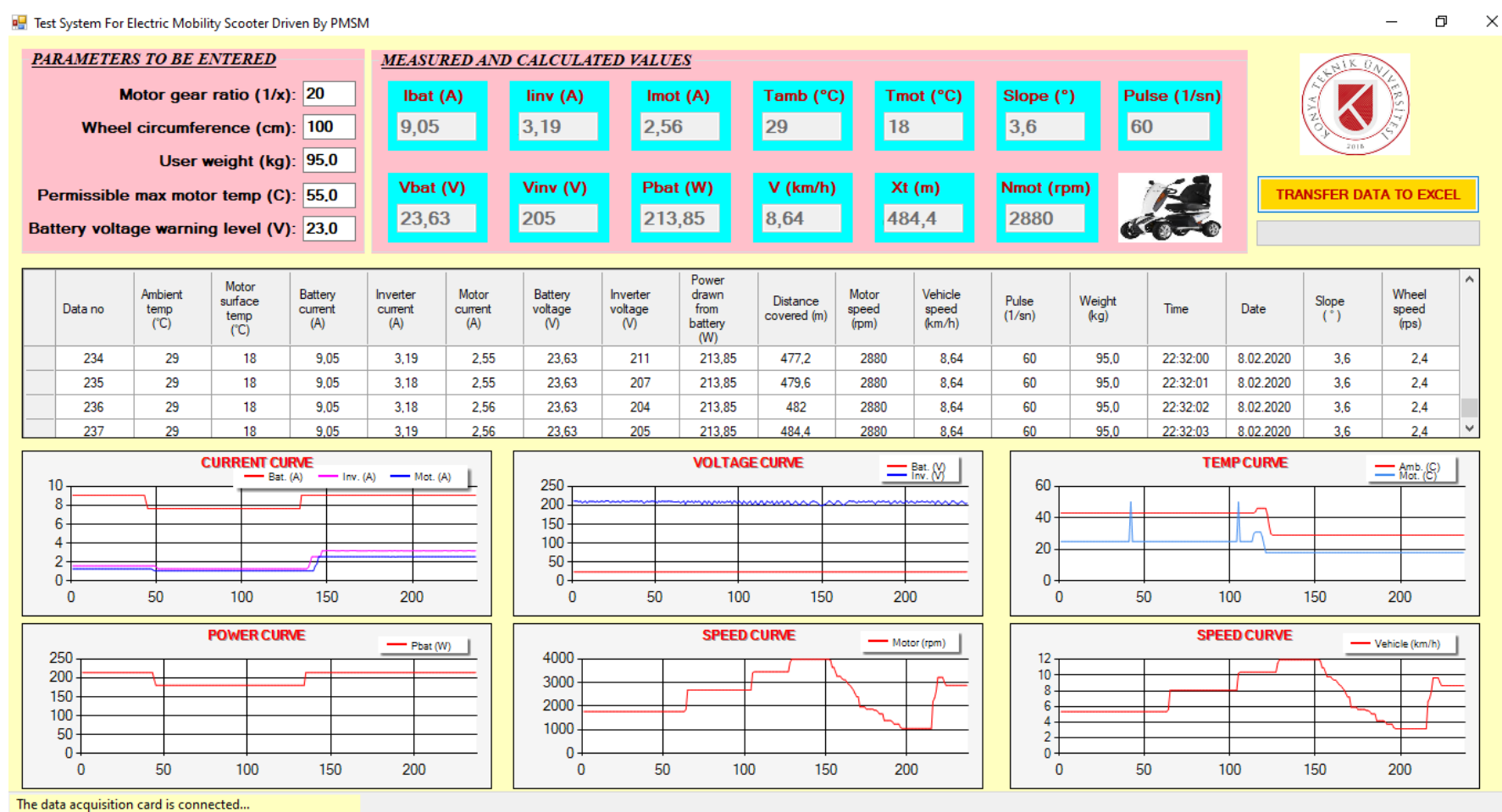

Fig. 5. Designed interface program.

The designed interface consists of 4 main sections: parameters section to be entered, measured and calculated values section, table section and graphic section.

In the parameters section to be entered, the battery voltage warning level can be determined in order to protect the batteries from deep discharge during the test or to examine the process until the battery voltage decreases to a certain value. When the battery voltage drops to the entered value, the user is warned with an audible warning. In order to prevent the motor from overheating or to examine the process until it reaches a certain value, the maximum allowable motor temperature section has also been added. In addition, in order to examine the effect of user weight on the measured parameters of the vehicle, it has also possible to enter the weight information of the person sitting in the vehicle seat during the test.

The instantaneous values of the measured and calculated total 13 quantities are displayed in the measured and calculated values section. The quantities are also recorded in the table section. A data number is assigned to each data set during recording. Thus, it is possible to examine the data both during and after the test. Moreover, the time, which elapsed from the moment the first data is received until the moment the last data is received, can be computed precisely. Thus, it is also possible to calculate the energy consumption value per $\mathrm{km}$ of the vehicle. All the data saved in the table section can be exported to Excel at any time.

10 of the measured and calculated quantities have grouped among themselves and collected in 6 graphs. The graphics, which are updated automatically after each incoming data, show how the change of the relevant quantity from the beginning of the test. In these graphs, the data are on the yaxis whereas the data numbers are on the x-axis. Since the data is updated every second, the data number also represents the total time in seconds since the start of the test.

9 out of 13 quantities (currents, voltages, temperatures, road slope and the number of pulses per second) in the measured and calculated values section are directly measurable quantities. The other 4 quantities (power drawn from the battery, motor speed, speed of the vehicle and the total road taken by the vehicle) are the quantities that should be calculated using the measured values.

The power drawn from the battery $\left(P_{b a t}\right)$, which is one of the calculated quantities, is calculated as in Eq. (1). $V_{b a t}$ and $I_{b a t}$ in Eq. (1) represent battery voltage and current drawn from the battery, respectively.

$$
P_{b a t}=V_{b a t} \cdot I_{b a t}
$$

In order to calculate the other three quantities, the revolution per second of the wheel $\left(N_{w}\right)$ must first be calculated using Eq. (2). In Eq. (2), $p_{t}$ refers to the total number of pulses produced by the Hall sensor in one second while $m_{n}$ indicates the total number of magnets mounted on the rear wheel.

$$
N_{w}=p_{t} / m_{n}
$$

In order to find the travelled total distance $\left(x_{t}\right)$ by the vehicle, the distance $\left(x_{s}\right)$ that was taken in one second must firstly be calculated. According to this, the distance travelled by the vehicle in meters in one second is calculated as in (3). $C_{w}$ in (3) refers to the circumference of the rear wheel in $\mathrm{cm}$.

$$
x_{s}=\left(N_{w} \cdot C_{w}\right) / 100
$$

The total covered distance that is updated every second is calculated as in (4). $\left(x_{(t-1)}\right)$ in (4) indicates the previous total covered distance value.

$$
x_{t}=x_{(t-1)}+x_{s}
$$

The instantaneous speed of the disabled vehicle in $\mathrm{km} / \mathrm{h}$ is: 


$$
v=x_{s} \cdot 3.6
$$

When considering the reducer ratio $\left(p_{g}\right)$, the motor's revolutions per minute $\left(N_{m}\right)$ is:

$$
N_{m}=60 \cdot N_{w} \cdot p_{g}
$$

\section{EXPERIMENTAL STUDIES}

In the experimental studies, the disabled vehicle, which is seen in Fig. 6 and previously introduced in [23] by the authors, was used. The vehicle was driven using the PMSM manufactured by Lenze with the code MCS06I41L.

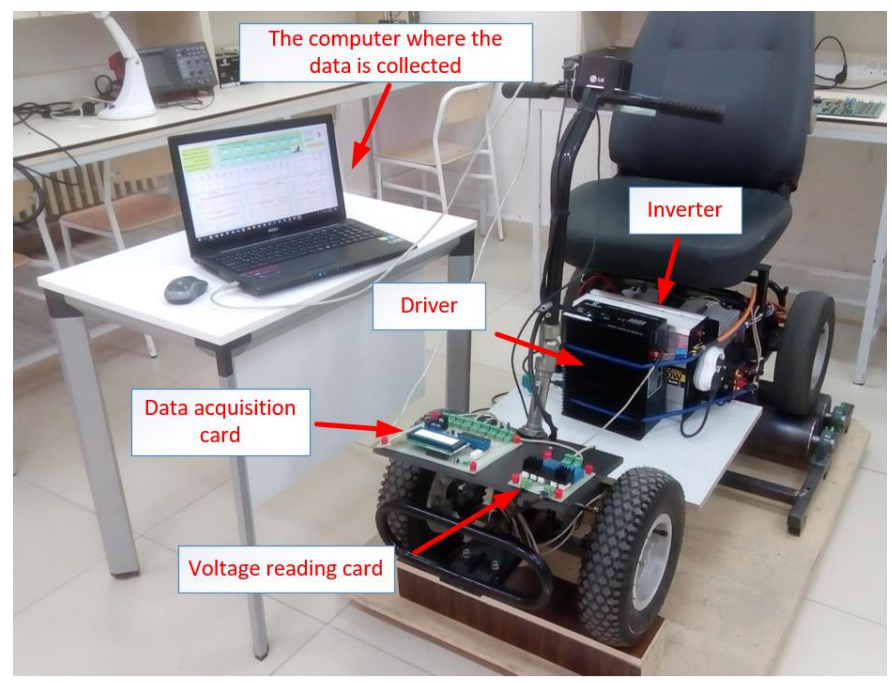

Fig. 6. Disabled vehicle and other components used in the experimental study.

Experimental studies were done in Alaeddin Keykubat Campus of Selçuk University. During the experiments, the motor was operated at $1000 \mathrm{rpm}$. Batteries were fully charged before each test to obtain more accurate comparison results. Experimental studies were carried out primarily without users, then with users of $35 \mathrm{~kg}, 50 \mathrm{~kg}, 70 \mathrm{~kg}$ and $95 \mathrm{~kg}$ respectively.

In order to examine the effect of the user's weight and the road slope, Route-1 in Fig. 7, where the slope is very close to zero and constant, was chosen. The average value of the slope on this route of $187 \mathrm{~m}$ is $0.21^{\circ}$. The slope sensor, which gives an analogue output, produces oscillating results due to the vibration and acceleration of the vehicle. To prevent the slope sensor from producing oscillating results due to the vibrating and accelerating movement of the vehicle, the vehicle was moved before point $\mathrm{A}$, was stopped after passing point $\mathrm{B}$.

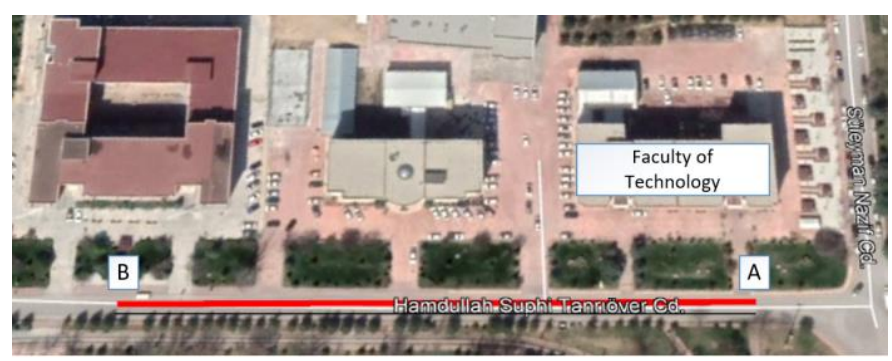

Fig. 7. Route-1.

The changes in the road slope of the Route-1 and in the power drawn from the battery along this route are given in Fig. 8.

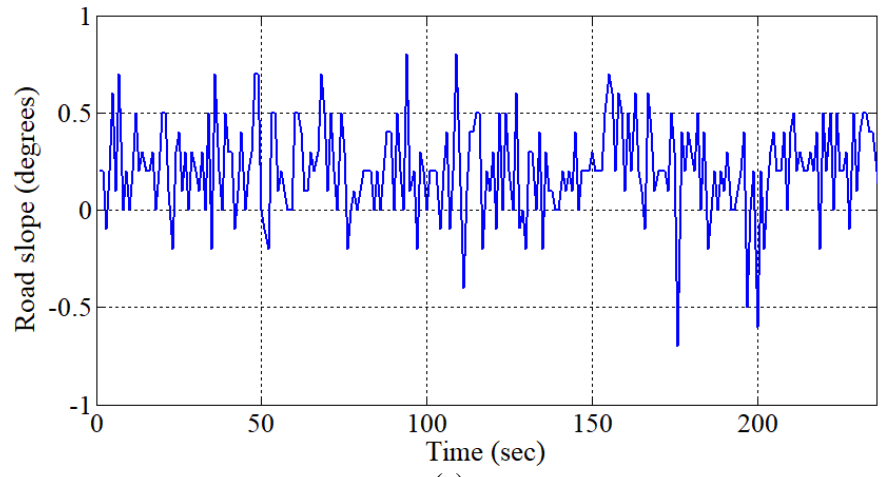

(a)

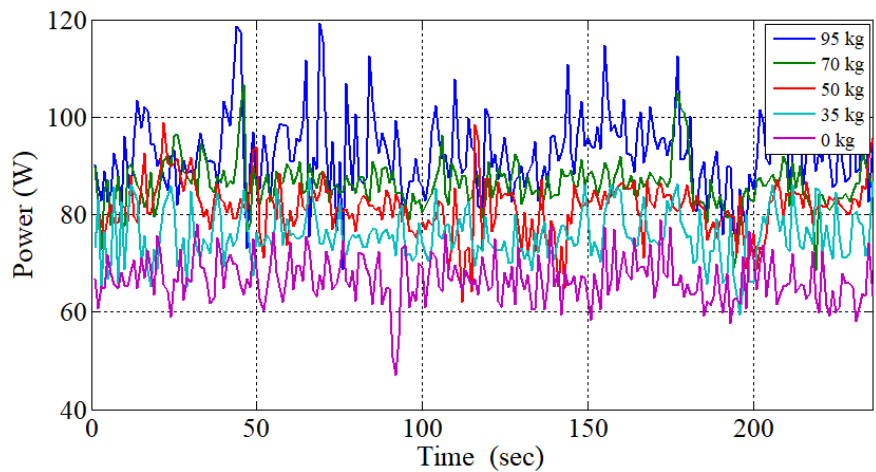

(b)

Fig. 8. Graphs of tests performed with users of different weights on Route-1.

(a) The road slope, (b) Power drawn from the battery.

When the power graphs in Fig. 8.(b) are examined, it is clearly seen that the power values drawn from the battery increase in parallel with the increasing user weight. The average value of the instantaneous power drawn from the battery in the test conducted along this route without a user is $66.68 \mathrm{~W}$. The average values of instantaneous power drawn from the battery at user weights of $35 \mathrm{~kg}, 50 \mathrm{~kg}, 70 \mathrm{~kg}$ and 95 $\mathrm{kg}$ are also $75.72 \mathrm{~W}, 81.34 \mathrm{~W}, 86.21 \mathrm{~W}$ and $92.53 \mathrm{~W}$, respectively. This relationship between user weight and average instantaneous power can also be seen in the graph in Fig. 9.

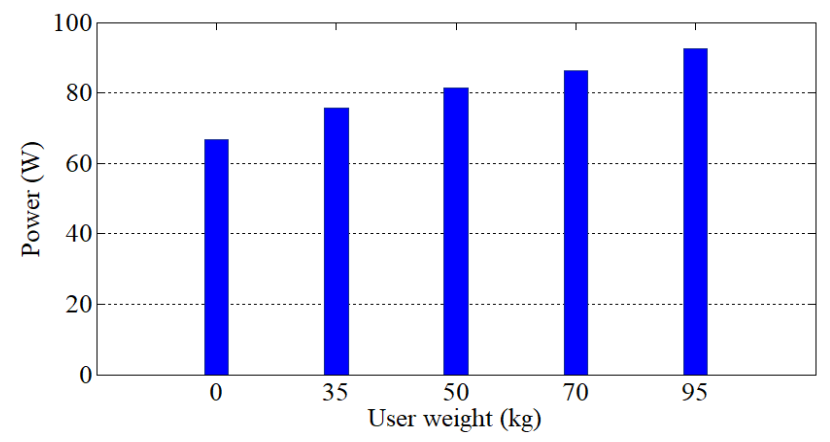

Fig. 9. Change of the average instantaneous power drawn from the battery according to the user weight in the tests performed in Route-1.

The total distance $\left(x_{t}\right)$, user weight $(m)$, total energy drawn from the battery $(W)$ and the energy that the vehicle must draw from the battery $\left(W / x_{t}\right)$ to travel $1 \mathrm{~km}$ are summarized in Table 1. The percentage increases in $W / x_{t}$ and $W / x_{t}$ values per kilogram obtained from the calculations based on the $m=0 \mathrm{~kg}$ state are also given in Table 1 as $\Delta\left(W / x_{t}\right)$ and $\Delta\left(W / x_{t}\right) / \Delta m$, respectively. 
TABLE I

ENERGY CONSUMPTION DATA OBTAINED FROM THE TEST PERFORMED IN ROUTE- $1\left(0.21^{\circ}\right)$.

\begin{tabular}{|c|c|c|c|c|c|}
\hline $\begin{array}{c}m \\
(\mathbf{k g})\end{array}$ & $\begin{array}{c}x_{t} \\
(\mathbf{k m})\end{array}$ & $\begin{array}{c}W \\
(\mathbf{W h})\end{array}$ & $\begin{array}{c}W / x_{t} \\
(W h / k m)\end{array}$ & $\begin{array}{c}\Delta\left(W / x_{t}\right) \\
(\%)\end{array}$ & $\begin{array}{c}\Delta\left(W / x_{t}\right) / \Delta m \\
(\%)\end{array}$ \\
\hline 0 & 0.187 & 4.45 & 23.80 & 0.00 & 0.00 \\
\hline 35 & 0.187 & 5.05 & 27.01 & 13.49 & 0.39 \\
\hline 50 & 0.187 & 5.33 & 28.50 & 19.75 & 0.39 \\
\hline 70 & 0.187 & 5.75 & 30.75 & 29.20 & 0.42 \\
\hline 95 & 0.187 & 6.17 & 32.99 & 38.61 & 0.41 \\
\hline
\end{tabular}

Undoubtedly, the increase in road slope will also have an effect on these rates. In order to see the effect of the road slope on these rates, this time the tests were performed on the $246 \mathrm{~m}$ long Route- 2 seen in Fig. 10. The average road slope of Route-2 is $1.44^{\circ}$. The tests were carried out from point $A$ to point B.

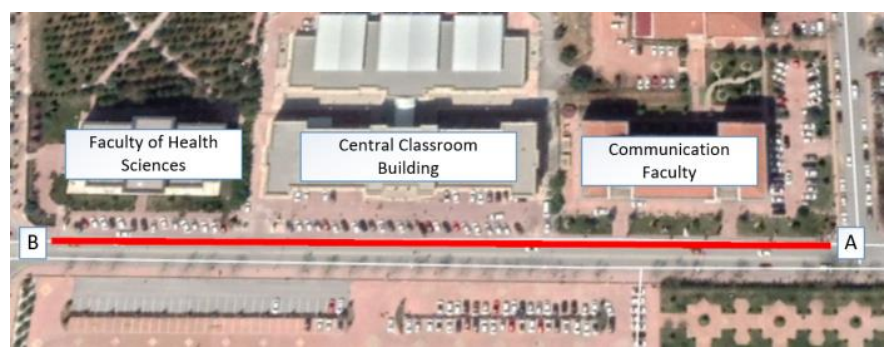

Fig. 10. Route-2.

The changes in the road slope of the Route-2 and in the power drawn from the battery along this route are given in Fig. 11.

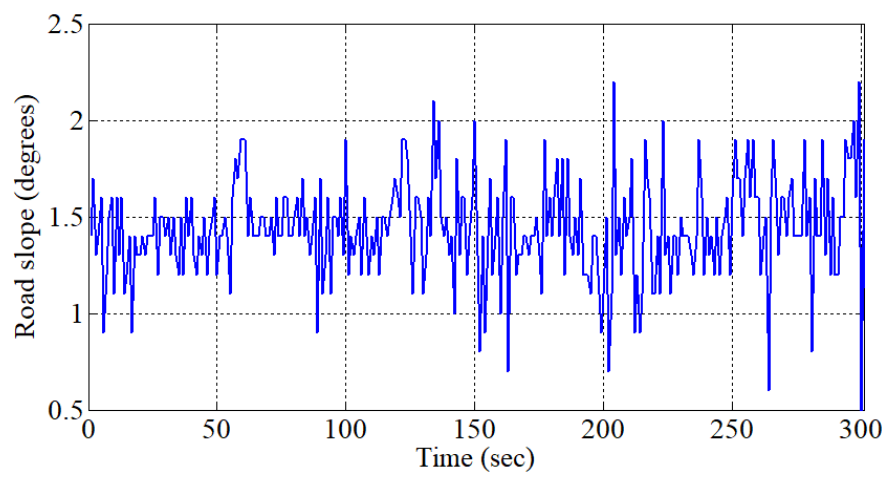

(a)

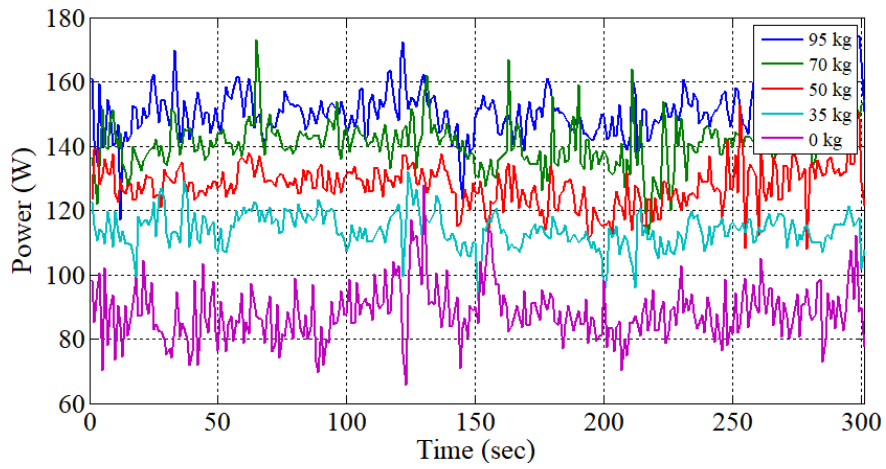

(b)

Fig. 11. Graphs of tests performed with users of different weights on Route-2. (a) The road slope, (b) Power drawn from the battery.
The average value of the instantaneous power drawn from the battery in the test conducted on Route- 2 without a user is $88.3 \mathrm{~W}$. The average values of instantaneous power drawn from the battery at user weights of $35 \mathrm{~kg}, 50 \mathrm{~kg}, 70 \mathrm{~kg}$ and 95 $\mathrm{kg}$ are also $113.83 \mathrm{~W}, 127.70 \mathrm{~W}, 140.75 \mathrm{~W}$ and $150.97 \mathrm{~W}$, respectively. This relationship between user weight and average instantaneous power can also be seen in the graph in Fig. 12.

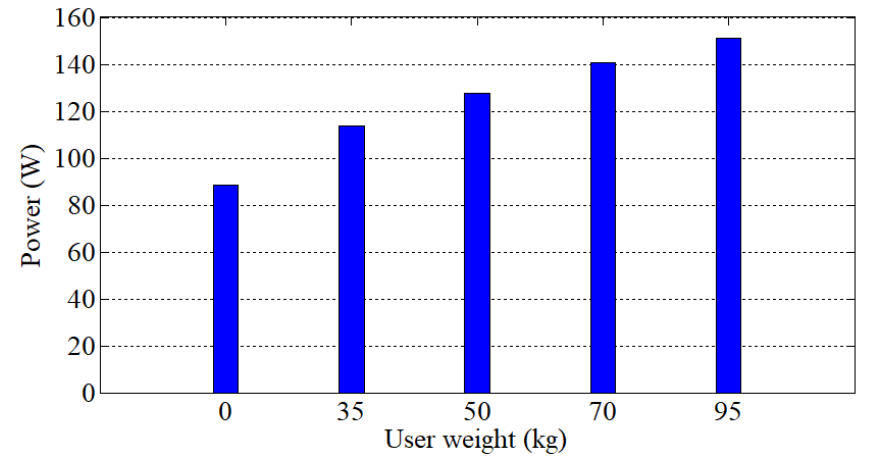

Fig. 12. Change of the average instantaneous power drawn from the battery according to the user weight in the tests performed in Route-2.

Energy consumption data of the tests performed in Route-2 are summarized in Table-2. The percentage increases in values, in which $\mathrm{Wh} / \mathrm{km}$ and $\mathrm{Wh} / \mathrm{km}$ per kilogram compared to test without users, are also given in Table 2.

TABLE II

ENERGY CONSUMPTION DATA OBTAINED FROM THE TEST PERFORMED IN ROUTE-2 $\left(1.44^{\circ}\right)$

\begin{tabular}{|c|c|c|c|c|c|}
\hline $\begin{array}{c}\boldsymbol{m} \\
(\mathbf{k g})\end{array}$ & $\begin{array}{c}\boldsymbol{x}_{\boldsymbol{t}} \\
(\mathbf{k m})\end{array}$ & $\begin{array}{c}\boldsymbol{W} \\
(\mathbf{W h})\end{array}$ & $\begin{array}{c}\boldsymbol{W} / \boldsymbol{x}_{\boldsymbol{t}} \\
(\mathbf{W h} / \mathbf{k m})\end{array}$ & $\begin{array}{c}\boldsymbol{\Delta}\left(\boldsymbol{W} / \boldsymbol{x}_{\boldsymbol{t}}\right) \\
(\boldsymbol{\%})\end{array}$ & $\begin{array}{c}\boldsymbol{\Delta}\left(\boldsymbol{W} / \boldsymbol{x}_{\boldsymbol{t}}\right) / \boldsymbol{\Delta m} \\
(\boldsymbol{\%})\end{array}$ \\
\hline 0 & 0.246 & 7.37 & 29.96 & 0.00 & 0.00 \\
\hline 35 & 0.246 & 9.52 & 38.70 & 29.17 & 0.83 \\
\hline 50 & 0.246 & 10.68 & 43.41 & 44.89 & 0.90 \\
\hline 70 & 0.246 & 11.77 & 47.85 & 59.71 & 0.85 \\
\hline 95 & 0.246 & 12.84 & 52.18 & 74.17 & 0.78 \\
\hline
\end{tabular}

\section{CONCLUSION AND DISCUSSION}

In this study, the effects of both road slope and user weight on the vehicle's energy consumption value in the disabled vehicle driven with PMSM were examined together. In this context, firstly, on the Route- 1 with an average slope of $0.21^{\circ}$, tests were carried out both with no load and with user weights of $35 \mathrm{~kg}, 50 \mathrm{~kg}, 70 \mathrm{~kg}$ and $95 \mathrm{~kg}$. In these tests on the Route-1, it was observed that every $1 \mathrm{~kg}$ increase in user weight caused an average increase of $0.40 \%$ in the amount of energy drawn from the battery per $\mathrm{km}$.

Then the same tests were repeated on the Route- 2 with a slope of $1.44^{\circ}$. In the test carried out on the Route-2, it was observed that every $1 \mathrm{~kg}$ increase in user weight caused an average increase of $0.84 \%$ in the amount of energy drawn from the battery per $\mathrm{km}$. When considering that this value is $0.40 \%$ on the road slope of $0.21^{\circ}$, it is seen that the increase in the road slope of $1.23^{\circ}$ causes a $110 \%$ increase in the energy consumption value per $\mathrm{kg}$.

By using these results, the numerical simulations of batteryoperated disabled vehicles can be calibrated and much more realistic simulation results can be obtained in future studies. 


\section{ACKNOWLEDGMENT}

This study is part of the project supported by Selçuk University Scientific Research Projects Coordination Office. The project number is 17101008 .

\section{REFERENCES}

[1] A. Akpunar, "Ergonomik Bir Elektrikli Tekerlekli Sandalye İçin Dişlisiz Ve Direkt Sürmeli Bir Elektrik Motor Tasarımı" Yüksek Lisans, Fen Bilimleri Enstitüsü, Muğla Üniversitesi, Muğla, 2007.

[2] S. Yang, M. Li, Y. Lin, and T. Tang, "Electric vehicle's electricity consumption on a road with different slope," Physica A: Statistical Mechanics and its Applications, vol. 402, pp. 41-48, 2014.

[3] J. Ju, Y. Shin, and E. Kim, "Intelligent wheelchair using head tilt and mouth shape," IET Electronics letters, vol. 45, no. 17, pp. 873-875, 2009.

[4] P. Ghule, M. Bhalerao, R. Chile, and V. G. Asutkar, "Wheelchair control using speech recognition," in 9th International Conference on Contemporary Computing (IC3), 2016: IEEE, pp. 1-6.

[5] R. Chauhan, Y. Jain, H. Agarwal, and A. Patil, "Study of implementation of Voice Controlled Wheelchair," in 3rd International Advanced Computing and Communication Systems (ICACCS), 2016, vol. 1: IEEE, pp. 1-4.

[6] D. Wang and $\mathrm{H}$. Yu, "Development of the control system of a voiceoperated wheelchair with multi-posture characteristics," in Intelligent Robot Systems (ACIRS), 2017 2nd Asia-Pacific Conference on, 2017: IEEE, pp. 151-155.

[7] M. F. Ruzaij, S. Neubert, N. Stoll, and K. Thurow, "Design and testing of low cost three-modes of operation voice controller for wheelchairs and rehabilitation robotics," in 2015 IEEE 9th International Symposium on Intelligent Signal Processing Proceedings, 2015: IEEE, pp. 1-6.

[8] P. S. Gajwani and S. A. Chhabria, "Eye motion tracking for wheelchair control," International Journal of Information Technology, vol. 2, no. 2, pp. 185-187, 2010.

[9] M. Jain, S. Puri, and S. Unishree, "Eyeball motion controlled wheelchair using IR sensors," World Acad. Sci. Eng. Technol. Int. J. Comput. Electr. Autom. Control Inf. Eng, vol. 9, no. 4, pp. 906-909, 2015.

[10] J. Sharma, M. Anbarasu, C. Chakraborty, and M. Shanmugasundaram, "Iris movement based wheel chair control using raspberry Pi-A state of art," in Power and Advanced Computing Technologies (i-PACT), 2017: IEEE, pp. 1-5.

[11] K. Arai and R. Mardiyanto, "Eyes based eletric wheel chair control system," International Journal of Advanced Computer Science and Applications (IJACSA), vol. 2, no. 12, 2011.

[12] G. Marins, D. Carvalho, A. Marcato, and I. Junior, "Development of a control system for electric wheelchairs based on head movements," in Intelligent Systems Conference (IntelliSys), 2017, 2017: IEEE, pp. 9961001.

[13] Ö. Deniz, A. A. Süzen, and A. Çetin, "Kafa Hareketleri İle Kontrol Edilebilen Tekerlekli Sandalye," in 4. Ulusal Meslek Yüksekokulları Sosyal Ve Teknik Bilimler Kongresi Burdur, Türkiye, 11-13 Mayıs 2017 2017.

[14] D. Kupetz, S. Wentzell, and B. BuSha, "Head motion controlled power wheelchair," in Proceedings of the 2010 IEEE 36th Annual Northeast Bioengineering Conference (NEBEC), 2010: IEEE, pp. 1-2.

[15] J. M. Ford and S. J. Sheredos, "Ultrasonic head controller for powered wheelchairs," Journal of Rehabilitation Research and Development, vol. 32, no. 3, pp. 280-284, 1995.

[16] F. A. Kondori, S. Yousefi, L. Liu, and H. Li, "Head operated electric wheelchair," in 2014 Southwest Symposium on Image Analysis and Interpretation, 2014: IEEE, pp. 53-56.

[17] V. Sankardoss and P. Geethanjali, "Design and low-cost implementation of an electric wheelchair control," IETE Journal of Research, pp. 1-10, 2019.

[18] N. Tanohata, H. Murakami, and H. Seki, "Battery friendly driving control of electric power-assisted wheelchair based on fuzzy algorithm," in Proceedings of SICE Annual Conference 2010, 2010: IEEE, pp. 15951598.

[19] N. Hashimoto, K. Tomita, A. Boyali, Y. Takinami, and O. Matsumoto, "Experimental study of the human factors when riding an automated wheelchair: supervision and acceptability of the automated system," IET Intelligent Transport Systems, vol. 12, no. 3, pp. 236-241, 2018.
[20] T. Wang, J. i. Kaneko, and K. Kojima, "Study on relevance between electric wheelchair riding comfort and user exposure to whole-body vibration," in Consumer Electronics (GCCE), 2017 IEEE 6th Global Conference on, 2017: IEEE, pp. 1-2.

[21] H. M. Hondori, P. Q. Trung, and L. Shih-Fu, "Simultaneous sensing and actuating for path condition monitoring of a power wheel chair," in Robotics and Mechatronics (ICRoM), 2013 First RSI/ISM International Conference on, 2013: IEEE, pp. 343-346.

[22] Y.-K. Kim, Y.-H. Cho, N.-C. Park, S.-H. Kim, and H.-S. Mok, "InWheel motor drive system using 2-phase PMSM," in Power Electronics and Motion Control Conference, 2009. IPEMC'09. IEEE 6th International, 2009: IEEE, pp. 1875-1879.

[23] F. A. Kazan and R. Akkaya, "Use of PMSM in Electric Mobility Scooter Propulsion," in International Conference on Engineering Technologies (ICENTE'19), Konya, Turkey, October 25-27, 2019.

[24] M. F. Ruzaij, S. Neubert, N. Stoll, and K. Thurow, "A speed compensation algorithm for a head tilts controller used for wheelchairs and rehabilitation applications," in 2017 IEEE 15th International Symposium on Applied Machine Intelligence and Informatics (SAMI), 2017: IEEE, pp. 000497-000502.

[25] B. Li, J. Zhang, H. Du, and W. Li, "Two-layer structure based adaptive estimation for vehicle mass and road slope under longitudinal motion," Measurement, vol. 95, pp. 439-455, 2017.

[26] R. Akkaya and F. A. Kazan, "Design and implementation of a test setup for electric mobility scooter for the disabled," Measurement and Control, vol. 52, no. 9-10, pp. 1434-1444, 2019.

\section{BIOGRAPHIES}

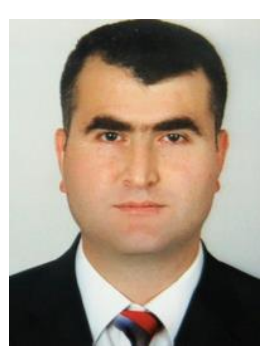

FATIH ALPASLAN KAZAN was born in Amasya, Turkey, in 1977. In 2002, he graduated from Electrical Education Department of Gazi University and started to work as a lecturer at Selçuk University. He completed his master's degree in Selcuk University, Institute of Science, Electrical and Electronics Engineering in 2009. He received his $\mathrm{PhD}$ degree from the Department of Electrical and Electronics Engineering of Konya Technical University in 2019. He has been working as Asst. Prof. in the Department of Aviation Electrical and Electronic of Selçuk University since 2020. His main interests are Avionic Systems, Microcontroller Applications, Measurement Systems, Circuit Design, and Motor Control.

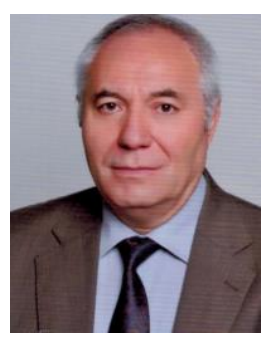

RAMAZAN AKKAYA was born in Aksaray, Turkey, in 1963. He received the B.S., M.S., and $\mathrm{PhD}$ degrees from Electrical Engineering of Y1ld1z Technical University, Istanbul, Turkey in 1986, 1988, and 1995, respectively. He worked as a Research Assistant between 1987 and 1995 and as an Assistant Professor between 1996 and 1998 at Yildiz Technical University Electrical Engineering Department. In 1998, he started to work at Selçuk University Electrical and Electronics Engineering Department. He became Associate Professor in 2010 and Professor in 2016 at the same university. He has been working as a Prof. Dr. in the Department of Electrical and Electronics Engineering at Konya Technical University since 2018. His main interests are Power Electronics and Applications, Control of Electric Drives, Electric Power Quality, and Renewable Energy Systems. 